\section{A letter from CMAJ's Editorial Advisory Board}

The CMAJ Editorial Advisory Board is concerned by the simultaneous dismissal of Dr. John Fletcher and the Journal Oversight Committee (JOC). ${ }^{1}$

Following the dismissal of a previous editor-in-chief, Dr. John Hoey, the CMAJ Governance Review Panel's final report ("the Pound report") ${ }^{2}$ recommended a new governance structure that had worked until 2011, when changes were suggested by the Canadian Medical Association (CMA).

Despite attempts to implement a collaborative model between the various parties, it appears that unresolvable tensions between the CMA, Joule, the JOC and the editor-in-chief culminated in the current distressing situation.

It is not clear to us why Dr. Fletcher and the JOC were dismissed so abruptly. We are concerned that the dismissals themselves and the process used have reduced the trust of CMA members in the future independence of the journal; CMA's poor track record in retaining CMAJ editors-inchief contributes to this loss of trust.

This lack of governance structure and the instability it creates means that $C M A J$ cannot effectively interview for the post of editor-in-chief. Although the CMA has created a task force to make recommendations on how CMAJ can remain competitive in the current climate, we do not have any assurances that its recommendations will endure the next time there is a major disagreement between CMAJ, CMA and Joule (or its next iteration).

We respectfully suggest that, for $C M A J$ to have the most viable future, the report and recommendations from the task force should be seen as having the same credibility as the Pound report. To facilitate this, the $C M A J$ Editorial Advisory Board advises:

1. that the task force have independent, third-party oversight on the process and content of the task force report
2. that there be a timetable for the task force, its deliverables and the engagement undertaken posted on CMAJ's website

3. that there be a deadline for a governance structure for CMAJ to include clarity on how future disagreements will be resolved.

The members of the Editorial Advisory Board are committed to ensuring that CMAJ's editorial and staffing issues are managed predictably and professionally. We wish to help the task force succeed, but we need assurance that our concerns will be addressed.

\section{CMAJ Editorial Advisory Board}

See www.cmaj.ca/site/misc/edboard.xhtml

\section{References}

1. Kelsall D, Patrick K, Stanbrook MB, et al. Upholding the integrity of your CMAJ. CMAJ 2016;188:E113-4.

2. CMAJ Governance Review Panel final report. Ottawa: Canadian Medical Association; 2006. Available: www.cmaj.ca/site/pdfs/GovernanceReview Panel.pdf

CMAJ 2016. DOI:10.1503/cmaj.1150105

\section{CMA Board of Directors responds}

The CMA Board of Directors is very pleased that the members of the $C M A J$ Editorial Advisory Board continue to work toward helping secure a sound future for $C M A J .{ }^{1}$ Its involvement in the work of the CMA Task Force on $C M A J$ has been most welcome and will continue to be an integral part of this continuing process.

The CMA board has the utmost confidence and respect for the work of the task force, which is being led by Dr. Chris Simpson, past president. Work is underway on the comprehensive consultation exercise that will begin soon. This consultation will identify best practices and result in recommendations on a new mission statement, goals and objectives for CMAJ.

Based on this process, the CMA will build a strong foundation, identifying the strategy and direction required for CMA publications. Regardless of the advances and changes that are proposed, CMAJ's editorial independence will remain sacrosanct.
On behalf of the CMA board, I commend and thank the members of CMAJ's Editorial Advisory Board for their continuing commitment to Canada's premier peer-reviewed medical journal. Their knowledge and expertise are invaluable to the work underway to strengthen $C M A J$ for the future.

\section{Brian Brodie MD}

Chair, CMA Board of Directors

\section{Reference}

1. CMAJ Editorial Advisory Board. A letter from $C M A J$ 's Editorial Advisory Board [letter]. CMAJ 2016;188:754.

CMAJ 2016. DOI:10.1503/cmaj.1150106

\section{Lyme Disease guidelines}

I was interested to read Zubek's letter in $C M A J .{ }^{1}$ Most doctors in Canada are aware of the National Guideline Clearinghouse (NGC), a federal agency of the United States Department of Health and Human Services responsible for providing the most up-to-date clinical guidelines to physicians.

The NGC also removes clinical guidelines that are no longer relevant, that do not meet the Institute of Medicine's standards for clinical practice guidelines, including a systematic review of the evidence, or that have not been revised in the past five years. ${ }^{2}$

In January 2016, the NGC removed the Infectious Diseases Society of America (IDSA) guidelines on Lyme disease for these reasons. ${ }^{3}$ In a scathing report on the standard of clinical guidelines in North America, the Institute of Medicine specifically referenced the IDSA guidelines on Lyme disease as a prime example of what not to do. ${ }^{4}$

Now, the only evidence-based, peer-reviewed guidelines on Lyme disease that conform to (and exceed) the Institute of Medicine's clinical guideline standards and are available on the NGC website, are the International Lyme and Associated Diseases Society guidelines for Lyme disease. ${ }^{5}$

Jane Bailey BSc $(\mathbf{H})$

Wolfville, NS 